\title{
Computational and experimental pore-scale studies of a carbonate rock sample
}

\author{
William Godoy ${ }^{1 *}$, Elizabeth M. Pontedeiro, ${ }^{1,2}$, Fernanda Hoerlle ${ }^{1}$, Amir Raoof ${ }^{2}$, \\ Martinus Th. van Genuchten ${ }^{2,3}$, José Santiago ${ }^{1}$, Paulo Couto ${ }^{1}$ \\ ${ }^{1}$ Civil Engineering Program - PEC/COPPE - LRAP, Federal University of Rio de Janeiro, Rio de Janeiro, Brazil. \\ ${ }^{2}$ Department of Earth Sciences, Utrecht University, Utrecht, The Netherlands. \\ ${ }^{3}$ Center for Environmental Studies, CEA, São Paulo University, UNESP, Rio Claro, SP, Brazil. \\ ${ }^{*}$ Corresponding author. E-mail: wmgodoy@petroleo.ufrj.br
}

\begin{abstract}
Carbonate rocks host several large water and hydrocarbon reservoirs worldwide, some of them highly heterogeneous involving complex pore systems. Pre-salt reservoirs in the Santos Basin off the south-east coast of Brazil, are an example of such rocks, with much attention focused on proper characterization of their petrophysical and multiphase flow properties. Since it is very difficult to obtain rock samples (coquinas) from these very deep reservoirs, analogues from north-eastern Brazil are often used because of very similar geological age and petrophysical properties. We used a coquina plug from an outcrop in a quarry in northeast Brazil to perform a comprehensive set of analyses. They included Scanning Electron Microscopy (SEM), Energy-Dispersive X-ray Spectroscopy (EDS), X-ray Diffraction (XRD), and micro-computed tomography $(\mu \mathrm{CT})$ image acquisition using a series of pixel sizes, as well as direct permeability/porosity measurements. Some of the experimental data were collected from the plug itself, and some from a small sample of the rock slab, including thin sections. Results included the carbonate rock composition and the pore system at different scales, thus allowing us to reconstruct and model the porosity and absolute permeability of the coquina using 3D digital imaging and numerical simulations with pore network models (PNMs). The experimental and numerical data provided critical information about the well-connected pore network of the coquina, thereby facilitating improved predictions of fluid flow through the sample, with as ultimate objective to improve hydrocarbon recovery procedures.
\end{abstract}

Keywords: Pore network modeling; Carbonate rock; Coquina; Absolute permeability; $\mu \mathrm{CT}$.

\section{INTRODUCTION}

Carbonate rocks host about $50 \%$ of worldwide hydrocarbon reserves (Vik et al., 2013). In Brazil, the pre-salt carbonate reservoirs accounted for $50 \%$ of total national oil production in 2018 (ANP, 2018). Although the annual production from the pre-salt reservoirs is increasing constantly, there are several challenges regarding their geological and petrophysical characterization (Corbett et al., 2017; Luna et al., 2016), as well as quantifying multiphase flow in their pore systems (Corbett et al., 2016). This because of the extremely heterogeneous nature of many carbonate rocks. One challenge of the pre-salt reservoirs is the difficulty to obtain samples for purposes of geological, sedimentological and petrophysical characterization. An alternative is to use analogue samples that are geologically similar to the pre-salt reservoir rocks (Corbett et al., 2016). For this many have used carbonate rocks samples from an outcrop in the northeast region of Brazil (Azambuja Filho et al., 1998), mostly to study their porosity and permeability properties. These samples, called coquinas (Tavares et al., 2015), contain large amounts of shells and as such exhibit considerable heterogeneity and anisotropy.

In order to study the petrophysical properties of carbonate rocks, with special focus on their pore networks, nondestructive visualization techniques such as X-ray computed microtomography, $\mu \mathrm{CT}$ (Blunt, 2001; Bultreys et al., 2015; Cnudde and Boone, 2013; Dal Ferro et al., 2013; Wildenschild and Sheppard, 2013) and scanning electron microscopy, SEM (de Boever et al., 2015; Fäy-Gomord et al., 2017; Hemes et al., 2015), have been widely used. Energy-dispersive X-ray spectroscopy (EDS) is also used often for qualitative (Goldstein et al., 2003) and even quantitative (Newbury and Ritchie, 2013) analyses of the composition of different rocks and soils. Although destructive, energy-dispersive X-ray diffraction (XRD) techniques are similarly important for qualitative/quantitative analyses (Hillier, 1994).

In our work we used $\mu \mathrm{CT}$ as an excellent non-invasive method for characterizing and quantifying rock structures and studying dynamic pore-scale processes. Digital reconstructions of image stacks are then used to represent the internal structure of a coquina sample, thereby providing connections between the different pores (i.e., pore bodies and throats) in a pore network, leading to a quantitative understanding of fluid behavior in the sample. An extremely important step after acquiring $\mu \mathrm{CT}$ images is the processing of generated data. This processing step can be done using one or more filters (e.g., anisotropic diffusion and/or non-local means filters) to correct and enhance the quality of the images. Non-local means filters (Buades et al., 2005) are especially popular when working with images of heterogeneous carbonate rocks (e.g., Shah et al., 2015).

Subsequent to treatment of the images using one or more filters, a segmentation step is needed to isolate the pore system from the rock matrix, thus allowing their digital reconstruction. Segmentation can be done using different algorithms (automated methods) or by direct analysis using optical microscopy or SEM (manual procedures), thus allowing one to separate between the pore spaces and the solid rock matrix (Al-Raoush and Willson, 2005; Wildenschild et al., 2002). The use of thin sections impregnated with blue epoxy resin helps to more accurately identify pore spaces, especially for detecting the intraparticle porosity of coquina samples. Although the use of visual segmentation methods requires some experience, they often improve the selection of regions where meso- and macro-pores are dominant, among other applications. The use of SEM as an auxiliary tool also guarantees the possibility of visualizing, with high resolution, regions that may become indistinct in $\mu \mathrm{CT}$ images generated with larger pixel sizes (Blunt et al., 2013; Bultreys et al., 2016). Several automated methods for segmen- 
tation are now available for different types of images (Andrä et al., 2013; Iassonov et al., 2009; Sezgin and Sankur, 2004).

After segmentation and subsequent skeletonization to define the pore structure in terms of pore bodies and pore throats, various approaches can be used for modeling the absolute permeability and related pore-scale transport processes. These include methods for solving the Navier-Stokes equations (or simplifications thereof), including Lattice Boltzmann methods (Jafari et al., 2011; Ramstad et al., 2010), traditional mesh-based computational fluid dynamics approaches (e.g., finite difference, finite volume and finite element methods) as described by Thijssen (2007) among others, as wll as pore network modeling (PNM) and related techniques (Blunt et al., 2013; Bultreys et al., 2015; Joekar-Niasar and Hassanizadeh, 2012; Raoof et al., 2013).

Several alternative approaches are available to estimate the absolute permeability from pore space characteristics, such as effective-medium approximations, EMAs (Doyen, 1988; Ghanbarian et al., 2018) and critical path analyses, CPAs (Ghanbarian et al., 2016; Katz and Thompson, 1986) techniques. The main difference between EMA and CPA techniques refers to the pore-throat size distribution: EMA approaches are better suited for media having relatively narrow pore-throat size distributions, while CPA techniques are best used for more heterogeneous media having broader pore-throat distributions (e.g., Ghanbarian et al., 2018).

Specific objectives of this study were to generate and study the pore-scale network of a real coquina plug using experimental and digital data, and to perform numerical fluid flow simulations based on porous networks based on 3D X-ray microtomography images obtained using different pixel sizes. Experimental data obtained for the plug and rock slab (taken from the same plug) using different techniques (permeameter/porosimeter, SEM-EDS and XRD measurements) were analyzed to improve identification of the pore system and the composition of the rock material. Our main objective was to construct the pore structure of a real coquina sample that serves as a geologically analogue of a Brazilian pre-salt reservoir rock, using experimental data, geological information, 3D modeling, and numerical simulation to identify and understand the main parameters that influence reconstruction of the pore system, which will allow us to simulate fluid flow and transport within the medium with good correlation with real data.

\section{MATERIALS AND METHODS}

In this section we provide a geologic description of the area where the carbonate rock sample for our study was taken, as well as its characterization regarding the pore system and mineralogical composition. Based on this information, we provide details about the digital reconstruction of its pore system and a brief description of the pore-scale network modeling approach used to estimate absolute permeability values.

\section{Carbonate rock sample description and preparation}

The carbonate rock sample selected for our study was taken from an outcrop of the Morro do Chaves Formation in the Sergipe-Alagoas Basin in north-east Brazil. The coquina samples from this site are close analogues in terms of porosity and permeability of coquinas taken from the pre-salt hydrocarbon reservoirs off the coast of south-east Brazil, such as the presence of well-connected meso- and macro-pores ranging from few micrometers up to several millimeters. The SergipeAlagoas Basin is located in the Brazilian states of Sergipe and Alagoas, and with a small portion in the state of Pernambuco Brazil (Fig. 1). Although the basins of Sergipe and Alagoas exhibit important differences in terms of their structure and stratigraphy (Thompson et al., 2015), it is possible to define the Sergipe-Alagoas Basin as a single entity (Campos Neto et al., 2007). The basin is known in that its outcrops include all sections of the Brazilian continental margin, with a total estimated area of over $44,000 \mathrm{~km}^{2}$. According to Campos Neto et al. (2007), the evolution of this basin is related to the separation of the Gondwana continent, with its subsidence occurring in the Rifte phase. At this stage the first tectonic pulse occurred, which commenced a sedimentary sequence during which the Morro do Chaves Formation was generated.

The Morro do Chaves Formation is defined by Azambuja Filho et al. (1998) as a carbonate succession that is interspersed with siliciclastic rocks of the Coqueiro Seco and Rio Pitanga formations. Located in the municipality of São Miguel dos Campos, in the state of Alagoas, the Morro do Chaves Formation currently corresponds to a quarry (mine) called Mina São Sebastião (Fig 1). The coquinas were formed by bivalves and non-marine ostracodes with varying percentages of terrigenous deposits. As detailed by Tavares et al. (2015), shells have different sizes and degrees of fragmentation, with facies in some cases containing bivalves in living or articulated positions. They noted that coquinas from Morro do Chaves have calcite as the main mineralogical component, while containing mostly mollusc shells. The rock matrix is composed of clay, siliciclastic sand (mainly quartz), as well as some lithoclasts of igneous, sedimentary and metamorphic rocks. According Tavares et al. (2015), six lithofacies can be identified in the

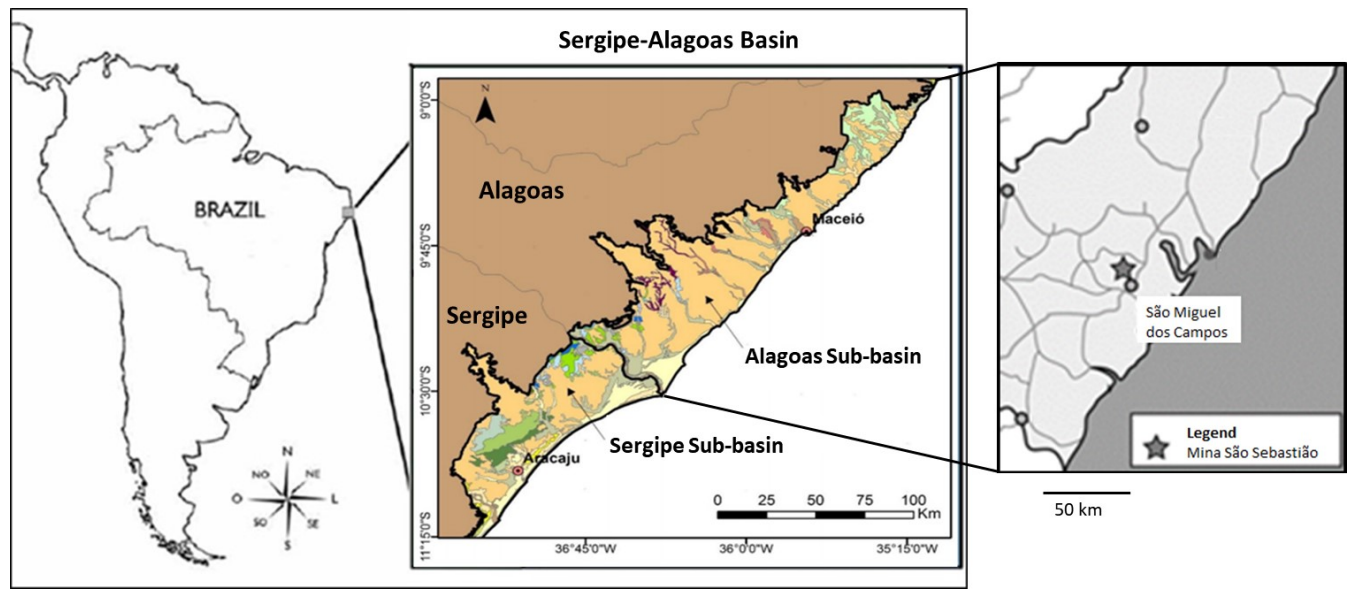

Fig. 1. Location of the Sergipe-Alagoas Basin, in the northeast region of Brazil, identifying the constituent sub-basins and the location of the quarry called Mina São Sebastião (in the city of São Miguel dos Campos), where the Morro do Chaves Formation is located. 
Morro do Chaves Formation, using both taphonomic (for shell fragmentation) and compositional (for the presence of micrite and siliciclastic sand) criteria.

A well-studied layer (Corbett et al., 2016; Luna et al., 2016) in the Morro do Chaves Formation (Fig. 2a), called Bed 2B (Fig. 2b) was selected. Corbett et al. (2016) pointed out that it is possible to use cross-stratification as evidence that the coquinas in this layer were deposited lakewards or lagoonwards as accreting bioclastic bars. A plug from that layer (Fig. 2b), designated as plug 1-34A (Fig. 2c), was selected for our study. The plug was prepared, flattened (top and bottom), cleaned with methanol and toluene, and placed in an oven at $60^{\circ} \mathrm{C}$ for 24 hours. The cleaning and drying processes were the same as adopted by Corbett et al. (2017), without needing a humiditycontrolled drying environment since the carbonate sample did not contain gypsum or solid hydrocarbon-like gilsonite or pyrobitumen. After preparation and cleaning, the plug was approximately $35 \mathrm{~mm}$ in diameter and $35 \mathrm{~mm}$ in length. Porosity and absolute permeability measurements were performed in the laboratory using a Wheaterford DV $-4000^{\mathbb{R}}$ gas porosimeter/permeater, while the porosity was measured using Helium (He) gas and the absolute permeability using Nitrogen gas $\left(\mathrm{N}_{2}\right)$. The equipment had a reliable range between $0.001 \mathrm{mD}$ and $40,000 \mathrm{mD}$ for absolute permeability measurements. We also measured the pore volume, grain density, mass, length and the actual diameter.

A $30-\mu \mathrm{m}$ thick thin section having dimensions of $70 \mathrm{~mm} \times$ $45 \mathrm{~mm}$ (Fig. 2d) was prepared, as well as a rock slab (Fig. 2e), from the cuts (top and bottom) of plug 1-34A after flattening of the surface of the sample. During preparation of the rock slab, a region of $10 \mathrm{~mm} \times 10 \mathrm{~mm}$ and $5 \mathrm{~mm}$ thickness (red region in Fig. 2e) was selected, cut, and then used to obtain various data. We used SEM to characterize the surface and to visualize the chosen pore spaces, and EDS for qualitative analysis and identification of the main elements composing the surface. SEM was performed in a Hitachi TM $3030^{\circledR}$ Plus low vacuum atmosphere and an acceleration voltage of $1.5 \mathrm{kV}$, and EDS using a Bruker XFlash ${ }^{\circledR}$ MIN SVE detector. The same region (shown in red in
Fig. 2e) was used to acquire $\mu \mathrm{CT}$ images using smaller pixel sizes (of 6.77 and $9.97 \mu \mathrm{m}$ ).

The remaining material after preparing the rock slab was powdered and taken for analysis using XRD techniques. Pulverization was carried out in an agate grinding mill followed by micronization in a McCrone mill. The powdered material weighted around 2.0 grams. XRD analyses were performed in a Bruker D8 ${ }^{\circledR}$ Advanced diffractometer using the following test conditions: $\mathrm{Cu}$ tube, $40 \mathrm{kV}$ nominal voltage and $40 \mathrm{~mA}$ current, Soller slit $2.5^{\circ}$, primary slit $0.6 \mathrm{~mm}$, secondary slit $5 \mathrm{~mm}$, LINXEYE $^{\circledR}$ linear detector with opening of 189 channels, Ni of $0.02 \mathrm{~mm}$, step size of 0.02 and speed of $1.1^{\circ} / \mathrm{min}$. Qualitative mineralogical analyses were done with Jade 9 software (with PDF-2 database). Quantitative analyses were carried out using the Rietveld Method within the TOPAS software.

\section{X-ray computed microtomography}

We used a Bruker X-ray computed microtomography Sky$\operatorname{scan}^{\circledR}$ model 1173 with a sealed X-ray source, tungsten target and a flat panel detector. The X-ray tube with tungsten filaments (Hamammatsu, model L9181) operates effectively between 40 and $130 \mathrm{kV}$ voltages with a maximum current of 200 $\mu \mathrm{A}$, reaching a maximum power of $8 \mathrm{~W}$ and a maximum focal size of $5 \mu \mathrm{m}$ (Machado et al., 2016). The detection system (Hamammatsu model C7942SK-05) consisted of a flat-panel sensor, operated with a maximum pixel array of $2240 \times 2240$, and with its recording carried out by an array of photodiodes forming electrical and digital signals.

Because of the large size of the plug, the size of the obtained pixel was approximately $9.97 \mu \mathrm{m}$. This value is the maximum supported by the equipment given the dimensions of the entire plug to perform the acquisition and reconstruction at feasible times (approximately $360 \mathrm{~min}$ for acquisition and $420 \mathrm{~min}$ for reconstruction of the $9.97 \mu \mathrm{m}$ pixel size $\mu \mathrm{CT}$ images involving a stack of images with 3,749 slices). For our study we obtained several $\mu \mathrm{CT}$ images with pixel sizes of $9.97 \mu \mathrm{m}, 18.17 \mu \mathrm{m}$, and $24.95 \mu \mathrm{m}$. The rock slab X-ray microtomography provided

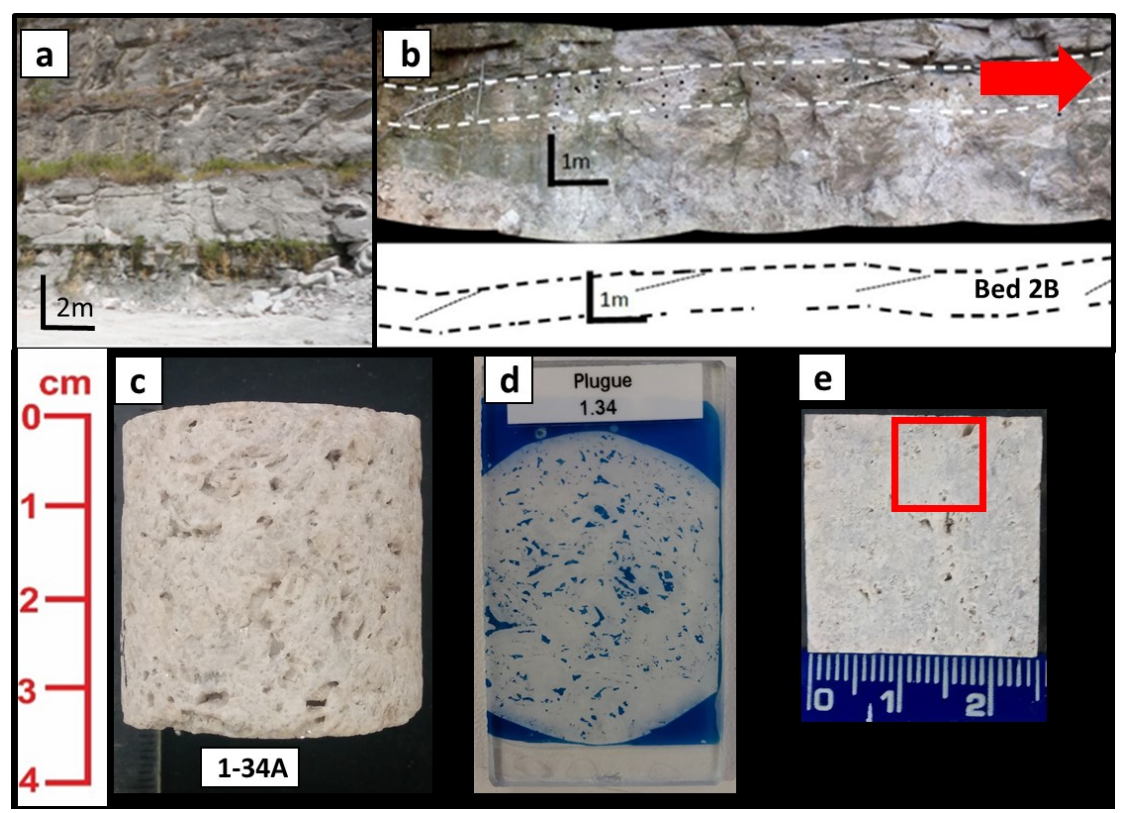

Fig. 2. (a) Image of the Morro do Chaves Formation in the Mina São Sebastião quarry of the city of São Miguel dos Campos; (b) identification of a layer (called Bed 2B) highlighted by the red arrow, from which the sample (named 1-34A) was taken; (c) image of the plug showing some vugular porosity in the sample; (d) thin section obtained from the cut of one end of the sample during flattening; and (e) rock slab prepared from the thin section, with the red square showing the region that was analyzed using SEM-EDS, XRD, and $\mu \mathrm{CT}$ with higher resolution. 
images with $6.77 \mu \mathrm{m}$ pixel size, close to the maximum limit supported by the equipment, and $9.97 \mu \mathrm{m}$ pixel size images. The selection of $9.97 \mu \mathrm{m}$ was deliberate since this value represents the smallest pixel size when using the whole plug. The acquisition parameters for the plug and the rock slab, with the different pixel sizes, are listed in Table 1.

After the data acquisition step, it was necessary to use a specific software from the equipment manufacturer, capable of converting information from the detector (based on an analysis of the attenuation suffered by a beam of incident radiation passing through, in this case, a carbonate rock) into data that is interpreted as digital images that can be loaded and interpreted by other software. We used for this purpose the Bruker NRecon ${ }^{\circledR}$ (v.1.6.9.4) and InstaRecon ${ }^{\circledR}$ (v 1.3.9.2) softwares, which allowed us to correct and treat the main image artefacts generated during acquisition, such as beam hardening and the presence of ring artefacts (Table 1). We further used a workstation with 2 Intel $^{\circledR}$ Xeon ${ }^{\circledR}$ E5-2640 v3 processors, $256 \mathrm{~Gb}$ RAM, and a NVIDIA ${ }^{\circledR}$ Quadro $^{\circledR}$ M4000 (8 GB RAM) GPU for $\mu \mathrm{CT}$ image acquisition and reconstruction.

\section{Digital reconstruction, image post-processing and segmentation}

A first step after $\mu \mathrm{CT}$ image acquisition is the application of specific filters to reduce noise from the images and to sharpen them. We used the Avizo ${ }^{\circledR} 9.5$ software to pass the non-local means filter (Fig. 3b) and to reconstruct the 3D model of the rock, as well as to segment the image, by means of the Interactive Thresholding function (Fig. 3c) after definition of the threshold value.

We next used an algorithm to detect the grey-level value that corresponds to the threshold value based on the selected Kittler and Illingworth (1986) segmentation method. The selected value was supported by analyses of SEM images and the greylevel histogram obtained from the $\mu \mathrm{CT}$ images. Verification of the pore systems impregnated with blue epoxy resin on the thin section was performed using a Zeiss Imager M2m ${ }^{\circledR}$ optical microscope with an increase of 2.5 times. Scanning was done by capturing images in mosaics, which were automatically joined by the microscope itself, resulting in a panoramic image of the entire thin section. Finally, we followed the methodology of Kaczmarczyk et al. (2011) for analysis of the grey value histograms using the Fytik ${ }^{\circledR}$ 0.9.8 software (Wojdyr, 2010) to generate Gaussian curves that represented the population of the pore system and the rock matrix itself. This to verify and evaluate the results by Kittler and Illingworth (1986) based on visual methods. The procedure was repeated for each image stack generated with different pixel sizes. The overlapping pixels were considered as part of the pore system. Imaging, 3D reconstruction, modeling and numerical simulations were carried out using a workstation with 2 Intel $^{\circledR} \mathrm{Xeon}^{\circledR}$ E5-2640 v4 processors, 512 Gb RAM, and a NVIDIA ${ }^{\circledR}$ Quadro $^{\circledR}$ P6000 (24 GB RAM) GPU.

\section{Pore network modeling}

After reconstruction of the 3D pore system, based on selection of the appropriate threshold value, the connected networks were analyzed to simulate fluid flow using an in-house code based in part on previous work by Raoof et al. (2013). We selected networks based on the size of the clusters (voxel count), since the numerical simulations were carried out assuming connectivity between the top and bottom of the sample (the $z$-axis), being the direction of the experiments with this plug. We kept the same procedure for the rock slab models (reconstructed from different pixel size $\mu \mathrm{CT}$ images). The Avizo ${ }^{\circledR} 9.5$ software was used to separate the larger networks and to generate topology information for subsequent reconstruction of the PNM. The pore domains were generated based on topology information provided by the software.

Pore bodies of the pore network were identified as the largest elements present in the network, with spherical geometry, while pore throats were identified and calculated based on

Table 1. $\mu \mathrm{CT}$ acquisition and reconstruction parameters.

\begin{tabular}{|l|c|c|c|c|c|}
\hline $\begin{array}{l}\text { Image pixel size } \\
(\mu \mathrm{m})\end{array}$ & $\begin{array}{c}\text { Source voltage } \\
(\mathrm{kV})\end{array}$ & $\begin{array}{c}\text { Current } \\
(\mu \mathrm{A})\end{array}$ & $\begin{array}{c}\text { Smoothing } \\
\text { factor }\end{array}$ & $\begin{array}{c}\text { Ring artefact correction } \\
\text { factor }\end{array}$ & $\begin{array}{c}\text { Filter: Al / Cu } \\
(\mathrm{mm} / \mathrm{mm})\end{array}$ \\
\hline 6.77 (rock slab) & 70 & 114 & 5 & 5 & $0.5 / 0.5$ \\
\hline 9.97 (rock slab) & 70 & 114 & 6 & 6 & $0.5 / 0.5$ \\
\hline 9.97 (plug) & 130 & 61 & 5 & 5 & $0.5 / 0.5$ \\
\hline 18.17 (plug) & 130 & 61 & 3 & 5 & $0.5 / 0.5$ \\
\hline 24.95 (plug) & 130 & 61 & 7 & 5 & $0.5 / 0.5$ \\
\hline
\end{tabular}
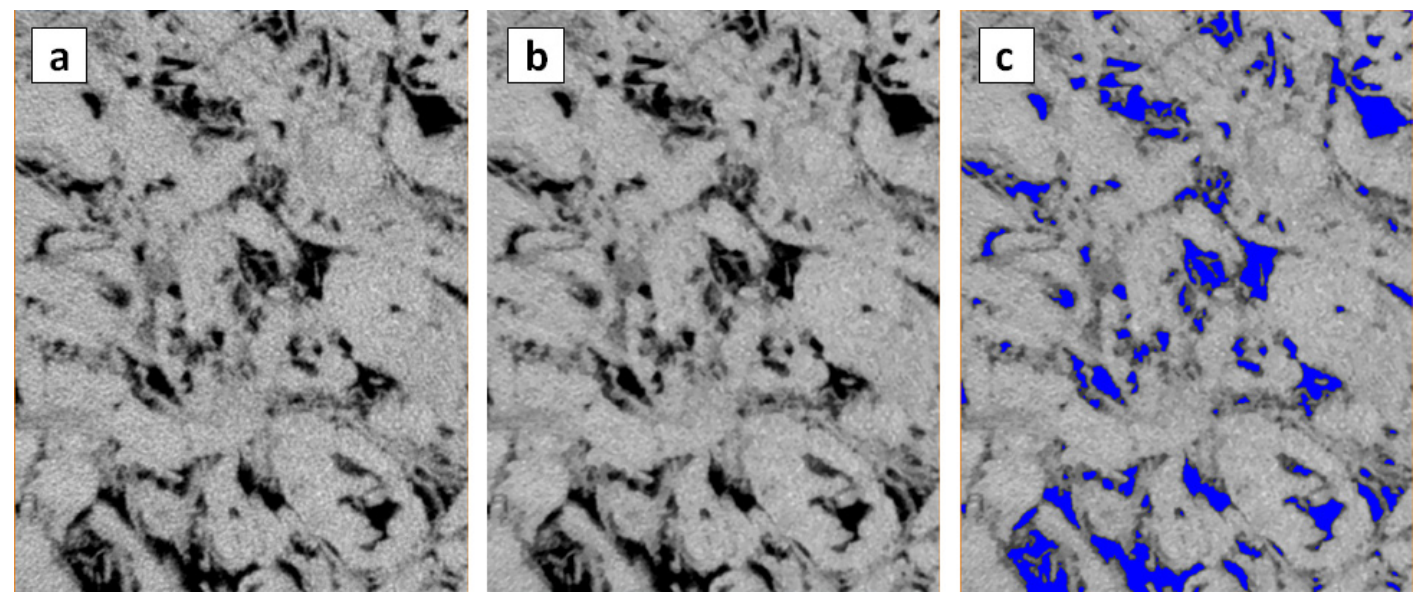

Fig. 3. Main steps related to treatment of (a) an original $\mu \mathrm{CT}$ image using (b) a non-local filter, and (c) interactive thresholding for segmentation purposes from Avizo ${ }^{\circledR}$ 9.5. 
being smaller spherical elements, depending upon their size and topology, as discussed by Fouard et al. (2006). The length of the pore throats was defined by the distance between two connected pore bodies, while their radii were calculated as a function of the mean radii of the spherical elements along the path between the two pore bodies. We calculated the radii of the pore throats using three different averaging methods: harmonic, geometric, and arithmetic. Absolute permeabilities were calculated using the generated pore structure, while saturated fluid flow within the network domain was simulated using a PNM algorithm.

Since extensive reviews of PNM techniques can be found in the literature (de Vries et al., 2017; Raoof and Hassanizadeh, 2010, 2012; Raoof et al., 2010, 2013), we present here only the main equations. The approach assumes laminar flow within the porous media, using Poiseuille's formula to obtain the volumetric flow rate within each pore:

$q_{i j}=\frac{\pi}{8 \mu} r_{i j}^{4} \frac{p_{i}-p_{j}}{l_{i j}}$

where $q_{i j}$ is the discharge through the pore throat between pore bodies $i$ and $j ; p_{i}$ and $p_{j}$ are pressures of the two adjacent pore bodies; $r_{i j}$ is the pore throat radius; $l_{i j}$ is the throat length, and $\mu$ is the fluid dynamic viscosity.

Considering incompressible flow, the volume balance for each pore body $i$ requires:

$\sum_{j}^{N_{i}} q_{i j}=\frac{\pi}{8 \mu} \sum_{j}^{N_{i}} r_{i j}{ }^{4} \frac{p_{i}-p_{j}}{l_{i j}}=0$

where $N_{i}$ is the pore coordination number of pore $i$. Applying this equation to each pore body results in a linear system of equations with a sparse, symmetric and positive-definite coefficient matrix, which is to be solved for the pore body pressures.

Next, considering the sample as a representative elementary volume (REV), the average pore water velocity, $\bar{v}$, can be calculated as (Raoof et al., 2013):

$\bar{v}=\frac{Q_{t o t} L}{V_{f}}$

where $Q_{\text {tot }}$ is the total discharge rate through the pore network, $L$ is the length of the pore network, and $V_{f}$ is the total volume of the fluid phase within the pore network. The total discharge rate can be calculated at the inlet or outlet of the pore network as the sum of all fluxes. Finally, the intrinsic permeability, $k$, of the sample can be determined using Darcy's law using the results from (3):

$k=\frac{\mu Q_{t o t} L}{A \Delta P}=\frac{\mu \bar{v} V_{f}}{A \Delta P}$

where $\mu$ is the fluid dynamic viscosity, $\Delta P$ is the pressure difference between the inlet and outlet pores, and $A$ is the crosssectional area of the pore network.

For our study we imposed a pressure differential of $5.0 \times$ $10^{-3} \mathrm{~Pa}$ between the upper and lower boundaries of the PNM along the z-axis. This small differential was adopted to guarantee laminar flow (low Reynolds number), an important assumption to solve Eqs. (1) to (4).

\section{RESULTS AND DISCUSSION}

Before presenting results of the various pore network calculations for the entire coquina plug, we first summarize data from the experimental tests, as well as results from the rock slab pore network numerical simulations.

\section{Experimental data}

The first results for the plug were obtained using the DV$4000^{\circledR}$ equipment, after the cutting, flattening and cleaning procedures. The measured values were used for comparison with estimates obtained digitally and numerically for the porosity and absolute permeability, respectively. Table 2 presents the main experimental results for plug 1-34A. The data are indicative of groundwater reservoirs, which generally have a relatively high porosity $(15-20 \%)$ and an intermediate permeability (150-650 mD), with relatively good connectivity between the various pores.

After this step we analyzed images of the thin section for the purpose of characterizing and identifying the coquina pore system. Fig. 4 shows images obtained with optical microscopy. The images show that the rock is formed by fragments of robust shells (Fig 4b), with the bioclast fragments varying in size from 1 to $8 \mathrm{~mm}$. The bioclasts are oriented moderately, with little fragmentation and only slight abrasion. A very few (about $2 \%$ ) siliciclastic grains were observed, sub-rounded, spherical and with an average size of $0.5 \mathrm{~mm}$.
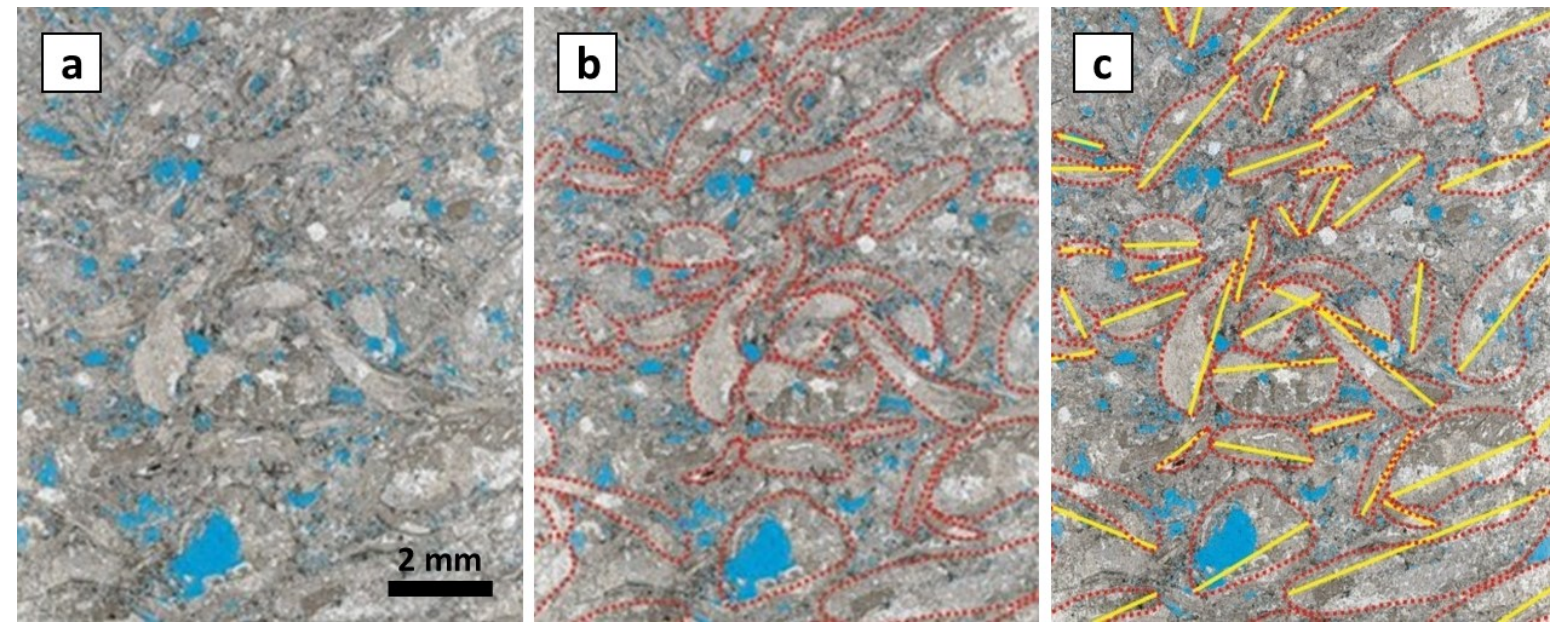

Fig. 4. Scanned images obtained with optical microscopy showing (a) blue epoxy resin filling the pores of the thin section, (b) highlighted in red the contours of bivalve shells, and (c) highlighted in yellow the size of the bivalve shells. 
Several dissolution phases generated the current porosity of the selected sample. The types of porosity present are intraparticle, interparticle, vugular and intercrystalline, with a predominance of interparticle and vugular porosities, and lower intraparticle porosities. The measured porosity and absolute permeability indicate good connectivity between the meso- and macro-pores. This information is important not only to aid in the segmentation step, but also to predict the absolute permeability through numerical simulations. The results suggest that fluid will flow preferably through pore spaces that can be reconstructed digitally, disregarding sub-resolution porosity that is identified using high-resolution images from very small sample volumes. Rabbani et al. (2017) recently estimated the absolute permeability from an analysis of thin sections, but their approach could not predict the behavior of carbonate rock samples having absolute permeabilities above $200 \mathrm{mD}$. For this reason we did not predict the permeability of our coquina based on an analysis of thin sections since the permeability was more than $600 \mathrm{mD}$.

SEM was used next to analyze the surface of the selected cut of the rock slab (red region in Fig. 2e) in order to evaluate the characteristics and dimensions of different pore structures. We selected a central area of the cut, which constituted the inner part of a bivalve shell. The images in Fig. 5 show a gradual zoom of this region, with increases of $50,150,300,800,1200$ and 2000 times the original size. Fig. 5a shows the presence of several large pores in the order of a few millimeters, externally to the center of the bivalve, while the largest zoom shows pores larger than $30 \mu \mathrm{m}$ (Fig. 5f). These observations suggest that optical microscope analyses of the thin section were consistent since they showed the same patterns: predominance of interparticle and vugular porosities in different regions. These results are important to understand the main aspects related to the pore size distribution and the connectivity of these pore systems.

Several regions were particularly challenging for analyzing the pore system and the rock composition. We selected a southern region from the cut rock slab to perform an EDS analysis. The analysis helped us to evaluate dubious regions, which could be interpreted visually as pores or as material with a lower attenuation coefficient in the $\mu \mathrm{CT}$ images, as well as providing a qualitative indication of the elements presented in the sample. Fig. 6a shows three well-identified regions (repre- sented by the letters $\mathrm{A}, \mathrm{B}$ and $\mathrm{C}$ above the arrows, in the image). The yellow arrow (A) indicates a pore that is a few $\mathrm{mm}$ wide, while the red arrow (B) points to a well-defined pore (in the center) surrounded by a region that is more poorly defined. That region has a grey-level quite similar to that of the area in blue (C), which clearly does not correspond to a pore. The EDS allowed us to identify the latter region (C) as being composed of siliciclastic material (Fig. 6d), which was already identified in the thin section.

Fig. $6 \mathrm{~b}$ provides a qualitative analysis using different colors indicating the main components of the sample: a blue area in the center and a predominantly pink region throughout the remaining area. A more refined analysis revealed the presence of calcium (Fig. 6c), silicon (Fig. 6d), oxygen (Fig. 6e) and carbon (Fig. 6f). Results suggest that the studied rock is composed mainly of calcium, oxygen and carbon (most likely Ca$\mathrm{CO}_{3}$ ), indicating that the coquina was probably formed by calcite as previously shown by Tavares et al. (2015) from evaluations of coquinas from the same Morro do Chaves formation.

In order to confirm the results above, an XRD-based qualitative and quantitative mineralogical analysis of the rock slab was performed using the Jade 9 software (with the PDF-2 database), and also with the Rietveld Method of the TOPAS software, respectively. The composition was defined as $99.8 \%$ calcite $\left(\mathrm{CaCO}_{3}\right)$, thus corroborating the EDS results. Another important result of the XRD analysis was that the grey-level regions associated with the siliciclastic materials were not significant in size, and not representative, thus reducing uncertainties in the automated segmentation procedure. These evaluations are important to verify possible grey level regions where the pore system may be interpreted erroneously during segmentation.

\section{Coquina rock slab modeling}

Based on insight from the experimental data, we proceeded with modeling the selected rock slab region. The $\mu \mathrm{CT}$ images of the thin section showed the presence of clear vugular porosity, as well as some intraparticle porosity. Fig. 7a shows the selected region (red square) that was used for the SEM, EDS and $\mu \mathrm{CT}$ images using two different pixel sizes, whose 3D reconstruction can be observed in Fig. 7b. The 3D reconstructions of the pore systems from the $6.77 \mu \mathrm{m}$ (Fig. 7c) and
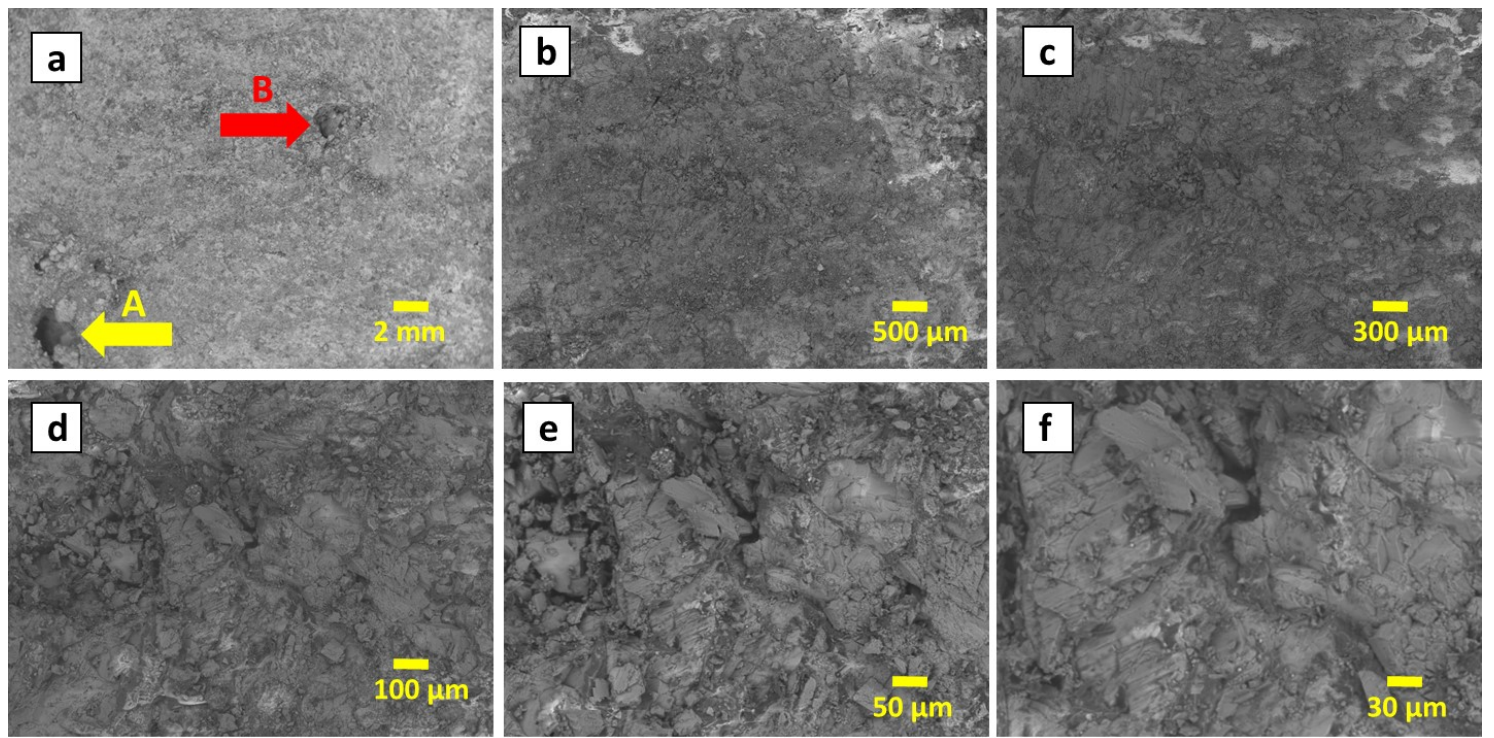

Fig. 5. SEM images obtained with an increase of (a) 50; (b) 150; (c) 300; (d) 800; (e) 1200, and (f) 2000 times the selected region of the rock slab. Fig. 5a shows the presence of two large pores of a few millimeter each (A and B). 



Fig. 6. (a) EDS image of the analyzed area, identifying three well-defined regions (A, a well-defined pore, B, a pore-centered region with dark grey level around it, and C, a dark grey level region similar to B but with no obvious pore boundary), (b) visual evaluation (colors) of the different components of the sample; (c) abundant presence of calcium, (d) presence of silicon in a small region (white dots), (e) oxygen, and (f) carbon distributed around the sample.

$9.97 \mu \mathrm{m}$ (Fig. 7d) pixel size $\mu \mathrm{CT}$ images showed that the vug was part of the largest pore system within the rock slab, and close to a region whose contours delimited a bivalve shell. This region showed very little porosity, regardless of the pixel size used for $\mu \mathrm{CT}$ imaging. Digital porosities obtained with the two different pixel sizes are shown in Table 3.

Next, we performed PNM simulations for laminar fluid flow in two digitally reconstructed rock slabs, to obtain the absolute permeability. As shown in Table 3, estimated values were much higher than the measured value of $639 \mathrm{mD}$ data for the entire plug (Table 2). The higher calculated values were to be expected because of the very small rock slab volume used in the $\mu \mathrm{CT}$ analysis. The volume presumably was much smaller than the minimum representative elementary volume (REV) needed for scale-independent permeability measurements (or calculations in this case). By comparison, the rock slab was large enough for the porosity calculations and measurements. We hence emphasize here that the PNM-based permeability estimates we obtained for the modeled rock slabs do not have an immediate direct relationship with the permeability measured using the entire coquina plug. To properly compare the measured absolute permeability of the plug, the PNM model should be applied to the entire plug.

We selected the largest pore systems from each reconstructed model, which are visualized in Fig. 7e (from the $6.77 \mu \mathrm{m}$ pixel size $\mu \mathrm{CT}$ images) and Fig. $7 \mathrm{f}$ (from the $9.97 \mu \mathrm{m}$ pixel size $\mu \mathrm{CT}$ images). The number of voxel-based clusters in Fig. 6e was higher than that found when we analyzed Fig. 7f, indicating that small clusters (represented by different colors) are only generated from higher-resolution images. Figs. $7 \mathrm{~g}$ and $7 \mathrm{~h}$ show the PNMs of the regions discussed previously. A first direct observation refers to the amount of pore bodies and pore throats generated for the construction of the PNMs. For construction of the model imaged with $9.97 \mu \mathrm{m}$ pixel size, we generated a much smaller number of points (Figs. $8 \mathrm{a}$ and $8 \mathrm{~b}$ ), although the topology of the system was maintained.

Some important conclusions can be drawn from the PNM simulations based on different pixel size $\mu \mathrm{CT}$ images. Most important, the results for porosity and absolute permeability were larger for the reconstructed model using higher resolution $\mu \mathrm{CT}$ images $(6.77 \mu \mathrm{m})$, thus suggesting that some pore bodies and pore throats were not included in the lower resolution $\mu \mathrm{CT}$ images $(9.97 \mu \mathrm{m})$, which must have influenced the numerical estimates. Differences between the absolute permeability values varied between $11.8 \%$ and $22.2 \%$, considering the different averages for pore-throat construction in each model. The pore throat radii based on harmonic means of the spherical elements that composed them were physically coherent, since they accounted for regions of constriction prior to modeling the pore throats using the PNM.

Table 2. Experimental results from plug 1-34A.

\begin{tabular}{|c|c|c|c|c|c|c|c|}
\hline Sample & $\begin{array}{c}\text { Pore Volume } \\
(\mathrm{cc})\end{array}$ & Porosity He (\%) & Permeability $\mathrm{N}_{2}(\mathrm{mD})$ & $\begin{array}{c}\text { Grain Density } \\
(\mathrm{g} / \mathrm{cc})\end{array}$ & Diameter $(\mathrm{cm})$ & Length $(\mathrm{cm})$ & Mass $(\mathrm{g})$ \\
\hline $1-34 \mathrm{~A}$ & 5.74 & 16.30 & 639.08 & 2.69 & 3.60 & 3.53 & 79.3 \\
\hline
\end{tabular}

Table 3. Porosity $(\phi)$ and absolute permeability $\left(k_{\mathrm{abs}}\right)$ estimated from the reconstructed coquina rock slab obtained with two different pixel sizes.

\begin{tabular}{|c|c|c|c|c|}
\hline PNM $-\mu$ CT Pixel size images $(\mu \mathrm{m})$ & \multirow{2}{*}{$\phi(\%)$} & Harmonic & Geometric & Arithmetic \\
\cline { 3 - 5 } & & 2,568 & 2,755 & 2,984 \\
\hline 6.77 & 8.43 & 2,137 & 2,422 & 2,746 \\
\hline 9.97 & 7.72 & 16.8 & 12.1 & 8.0 \\
\hline Difference $(\%)$ & 8.4 & & & \\
\hline
\end{tabular}





Fig. 7. (a) Image of the selected area for $\mu \mathrm{CT}$, indicating with a red arrow the presence of vugular porosity; (b) 3D volume reconstruction of the region using $6.77 \mu \mathrm{m}$ pixel size $\mu \mathrm{CT}$ images, with the red arrow highlighting the same vug as in Fig.6a; (c) 3D segmentation and reconstruction of the pore region of the sample, with the right upper extremity being the assimilated vug and a central region with lower porosity showing well-defined bivalve contours from the $6.77 \mu \mathrm{m}$ pixel size $\mu \mathrm{CT}$ images; (d) same from the $9.97 \mu \mathrm{m}$ images (e) selection of the largest pores from the $6.77 \mu \mathrm{m} \mu \mathrm{CT}$ images; (f) same from the $9.97 \mu \mathrm{m}$ images; (g) PNM generated with the largest pores from the $6.77 \mu \mathrm{m}$ pixel size $\mu \mathrm{CT}$ images; and (h) same from the $9.97 \mu \mathrm{m}$ images.
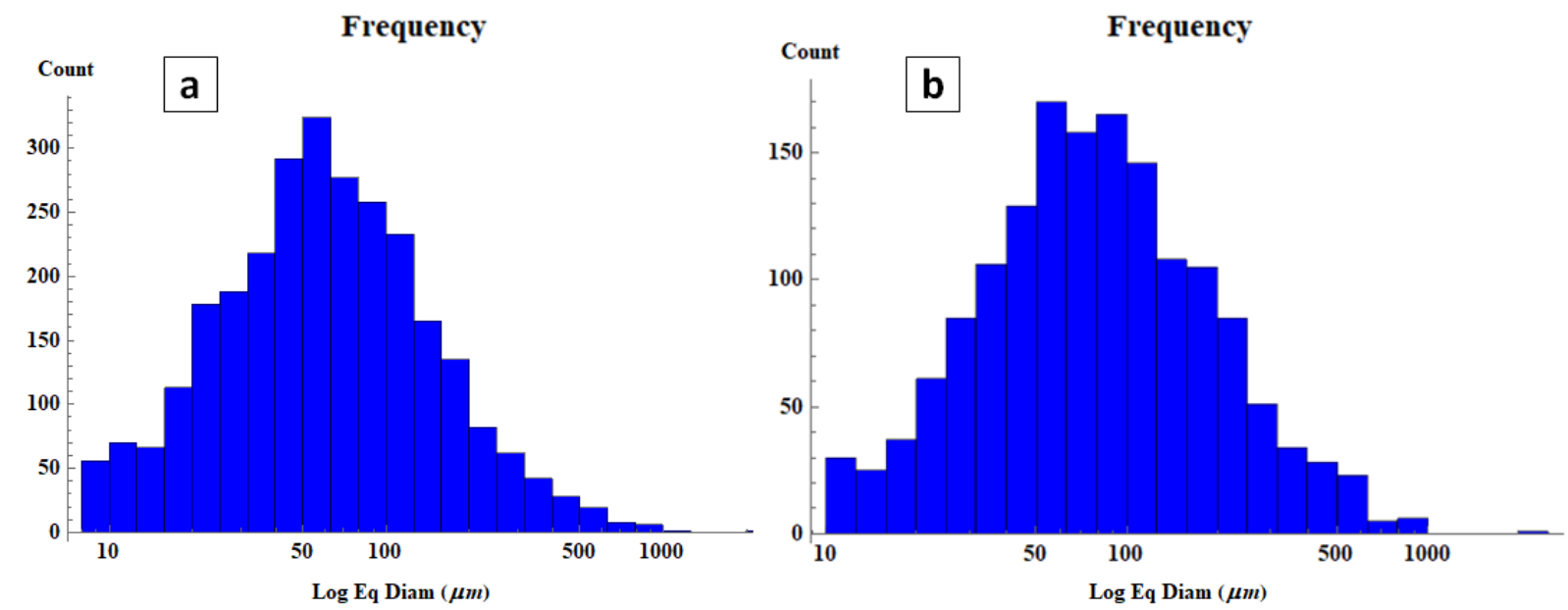

Fig. 8. Pore size frequency distributions (equivalent diameters) of the digital pore system of the rock slab obtained using (a) $6.77 \mu \mathrm{m}$ and (b) from $9.97 \mu \mathrm{m} \mu \mathrm{CT}$ images. Notice a much larger number of spherical elements in the reconstructed model using the higher resolution.

An analysis of the region with the greatest pressure differential, which was responsible for most of the fluid flow, is shown in Fig. 9. The plots visualize the length of the pore throats and the radii of the pore bodies for the slab reconstructed PNM using $6.77 \mu \mathrm{m}$ (Fig. 9a) and $9.97 \mu \mathrm{m}$ (Fig. 9b) pixel size $\mu \mathrm{CT}$ images as obtained with the Paraview ${ }^{B}$ software (Ayachit, 2015). A larger number of pore bodies and pore throats are apparent when using higher resolution $\mu \mathrm{CT}$ images, which leads to higher absolute permeability values. The images in Fig. 8 were generated from the models whose pore throats were calculated using harmonic means of their constituent spherical elements. The smaller pore throat diameters for both models can be seen in Fig. 9c and Fig. 9d, as well as the pressure (ranging from 0 to $5.0 \times 10^{-3} \mathrm{~Pa}$ ) in each pore body of this region. The simulation results indicate that fluid in this rock slab flows preferably through the mesopores and macropores.

\section{Coquina plug modeling}

After analysis of the rock slab, we similarly performed an analysis of the coquina plug in its entirety. Our objective was to estimate its petrophysical properties as well as to study PNM performance for a heterogeneous and complex pore system involving a large number of mesopores and macropores. We selected for this purpose the $\mu \mathrm{CT}$ images generated using three different pixel sizes of $9.97,18.17$, and $24.95 \mu \mathrm{m}$, thus testing the effects of resolution on the calculated parameters. Table 4 presents results of the 3D modeling scenarios and the experimental data of the selected petrophysical properties. Regarding porosity, the pore network reconstructed with higher resolution $\mu \mathrm{CT}$ images clearly presented better results when comparing the digital estimates to the measured data in Table 1. The same is true for the absolute permeability estimates using PNM. 

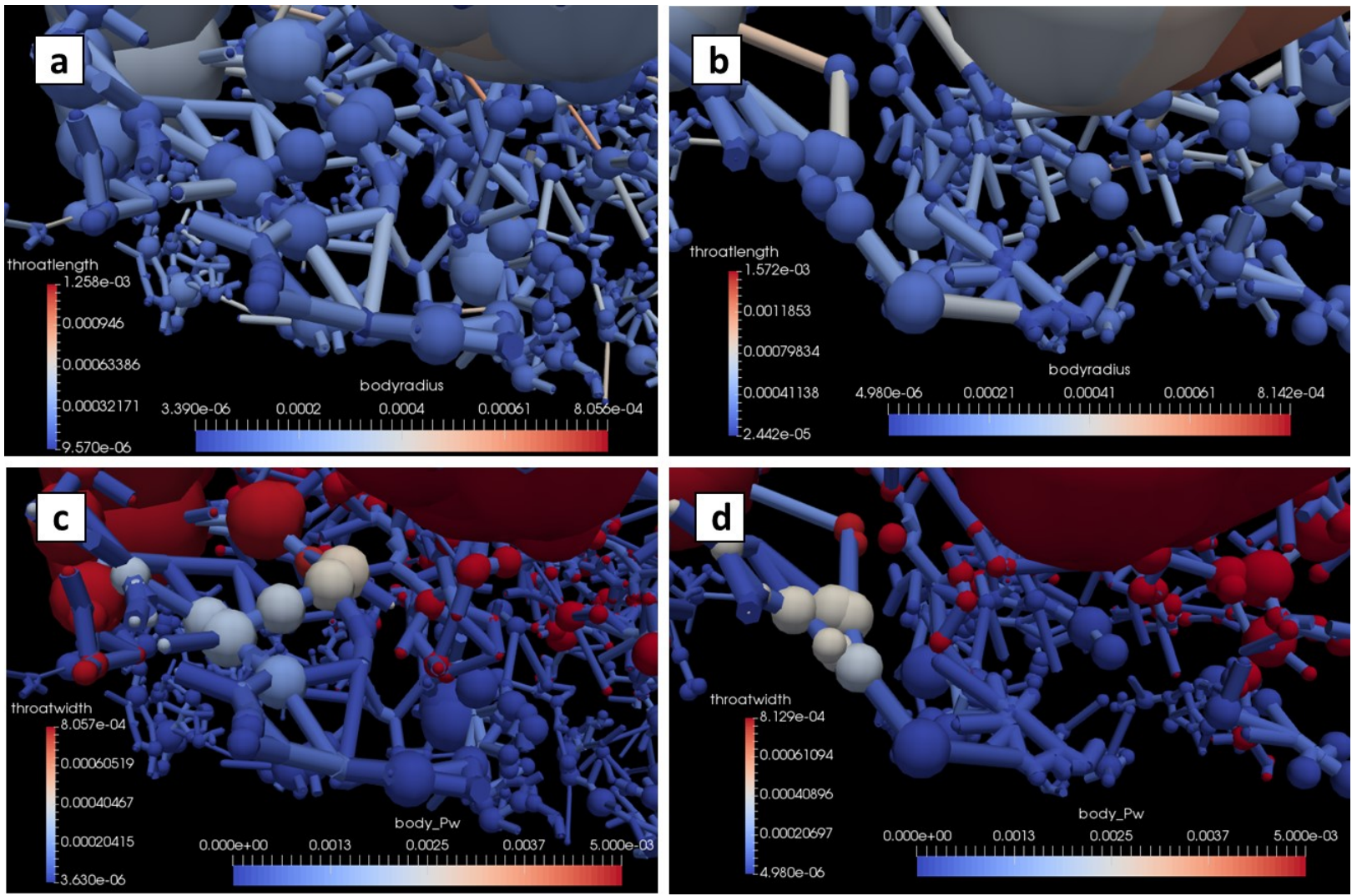

Fig. 9. PNMs of the reconstructed slab (a) from the $6.77 \mu \mathrm{m}$ pixel size $\mu \mathrm{CT}$ images, and (b) from the $9.97 \mu \mathrm{m}$ images, showing the distributions of pore radii and pore lengths. PNMs of the regions with greater pressure differentials between pore bodies following numerical simulation of fluid flow, as well as of the diameters of the pore throats in these regions, using (c) $6.77 \mu \mathrm{m}$ pixel size $\mu \mathrm{CT}$ images and (d) 9.97 $\mu \mathrm{m}$ images. The length and pressure units are $\mathrm{m}$ and $\mathrm{Pa}$, respectively.

Table 4. Porosity $(\phi)$ and absolute permeability $\left(k_{\text {abs }}\right)$ of the reconstructed coquina plug using PNM.

\begin{tabular}{|l|c|c|c|c|}
\hline $\begin{array}{l}\text { PNM }-\mu \mathrm{CT} \\
\text { Pixel size } \\
\text { images }(\mu \mathrm{m})\end{array}$ & \multirow{2}{*}{$\phi(\%)$} & \multicolumn{3}{|c|}{$k_{\text {abs }}(\mathrm{mD})$} \\
\cline { 3 - 5 } & & Harmonic & Geometric & Arithmetic \\
\hline 9.97 & 12.4 & 548.3 & 953.9 & $1,236.9$ \\
\hline 18.17 & 11.3 & 480.5 & 911.5 & $1,419.0$ \\
\hline 24.95 & 10.0 & 464.9 & 848.4 & $1,283.9$ \\
\hline Experimental & 16.3 & \multicolumn{3}{|c}{639.1} \\
\hline
\end{tabular}

Another important point refers to the average used to calculate the pore throats, based on the spherical elements that do not represent pore bodies on the models. Harmonic averaging gave the best results compared to the measured data, presenting a percentual difference of $14.2 \%, 24.8 \%$, and $27.3 \%$ for the PNM based results using $\mu \mathrm{CT}$ images with $9.97 \mu \mathrm{m}, 18.17 \mu \mathrm{m}$, and $24.95 \mu \mathrm{m}$ pixel size, respectively. We note here that the comparison between the PNM and the measured data for the entire plug does not require some REV verification since the experimental results were measured also on the entire plug.

Fig. 10 shows frequency distributions of the generated pore throats and pore bodies. The results indicate that the total number of pore bodies and pore throats for the model using higher resolution $\mu \mathrm{CT}$ images is more than 60 times larger than obtained with the lower resolution $\mu \mathrm{CT}$ images. This impressive increase relates to the capacity to recreate pore bodies and pore throats that are not detectable from lower resolution $\mu \mathrm{CT}$ images, as can be seen in Fig. 10d, 10e, and 10f, which presents the range of pore throat radii (in $\mathrm{m}$ ) for the models based on $\mu \mathrm{CT}$ images with $9.97 \mu \mathrm{m}, 18.17 \mu \mathrm{m}$, and $24.95 \mu \mathrm{m}$, respectively.
We next present PNM results for plug I-34A obtained with the intermediate resolution $(18.17 \mu \mathrm{m}$ pixel size $\mu \mathrm{CT}$ images $)$ and assuming the harmonic averages of the pore throats as shown in Fig. 11. The input and output boundaries were implemented based on the selection of $2 \%$ of the plug length, which leads to a well-defined layer for fluid entrance. As expected, some overlap occurred of the distributions of the pore bodies and pore throats, but with the largest pore throats being linked to the largest pore bodies, thus indicating good results regarding the PNM generation methodology. A selected few pore throats were several $\mathrm{mm}$ wide, which created regions for considerable fluid flow between the two linked pore bodies. However, the majority of pore throats remained within the $\mu \mathrm{m}$ range. The larger pore throats were important to preserve connections between vugs, thus creating preferential paths for fluid flow.

We also compared PNM results (all using harmonic averages of the pore throat radii) obtained with the different resolutions. Fig. 12 shows the final generated pore network and the calculated pressure fields. Results indicated that part of the well-connected network could not be generated using lower resolution $\mu \mathrm{CT}$ images. Still, in terms of fluid flow, the PNM captured important connections between mesopores and macropores since the calculated absolute permeabilities values (as shown in Table 4) were close to the measured value. The three PNM simulations showed specific regions with higher pressure drops, which were preferably accessed by fluid during the flow experiment. Fig. 12 further shows that the number of pore bodies and pore throats increases immensely as the $\mu \mathrm{CT}$ images resolution increased.

Another important result relates to the possibility to conduct numerical experiments using relatively large sample volumes. 



Fig. 10. Pore size frequency distributions (equivalent diameters) of the digital pore system of the plug obtained using (a) $9.97 \mu \mathrm{m}$, (b) 18.17 $\mu \mathrm{m}$, and (c) $24.95 \mu \mathrm{m} \mu \mathrm{CT}$ images; and the range of pore throat radii (scale in $\mathrm{m}$ ) found with the models generated using (d) $9.97 \mu \mathrm{m}$, (e) $18.17 \mu \mathrm{m}$, and (f) $24.95 \mu \mathrm{m} \mu \mathrm{CT}$ images.

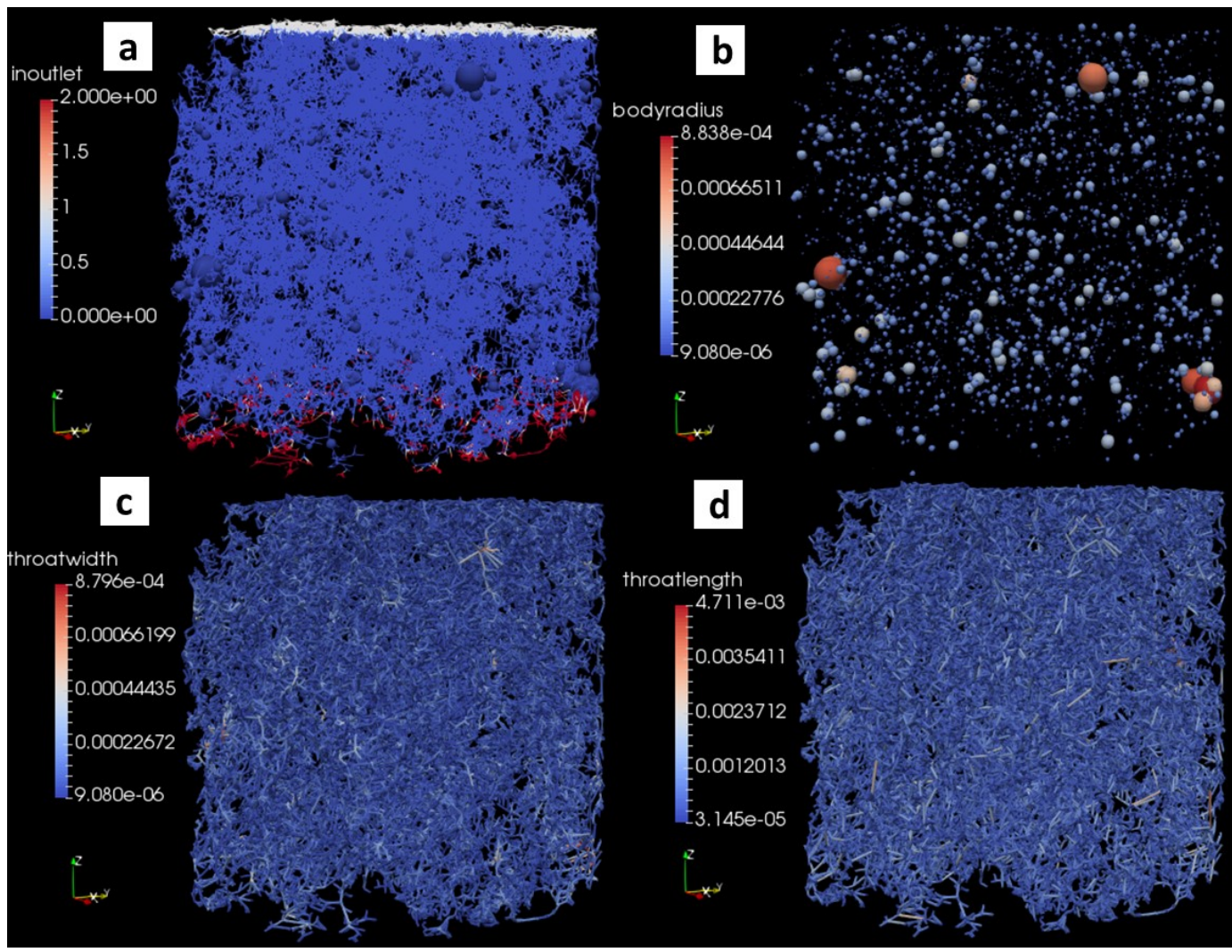

Fig. 11. PNM results for plug 1-34A based on $18.17 \mu \mathrm{m} \mu \mathrm{CT}$ images presenting: (a) input (white region) and output (red region) boundaries for the fluid flow numerical simulations, and ranges of (b) pore body radii, (c) pore throat radii, and (d) pore throat lengths (scales are in $\mathrm{m}$ ).

We showed that this is feasible despite the computational demand. The use of relatively large plugs avoids non-representative results, especially for the absolute permeability in view of the required REV. This characteristic is crucial when upscaling results from plugs to cores and beyond. 


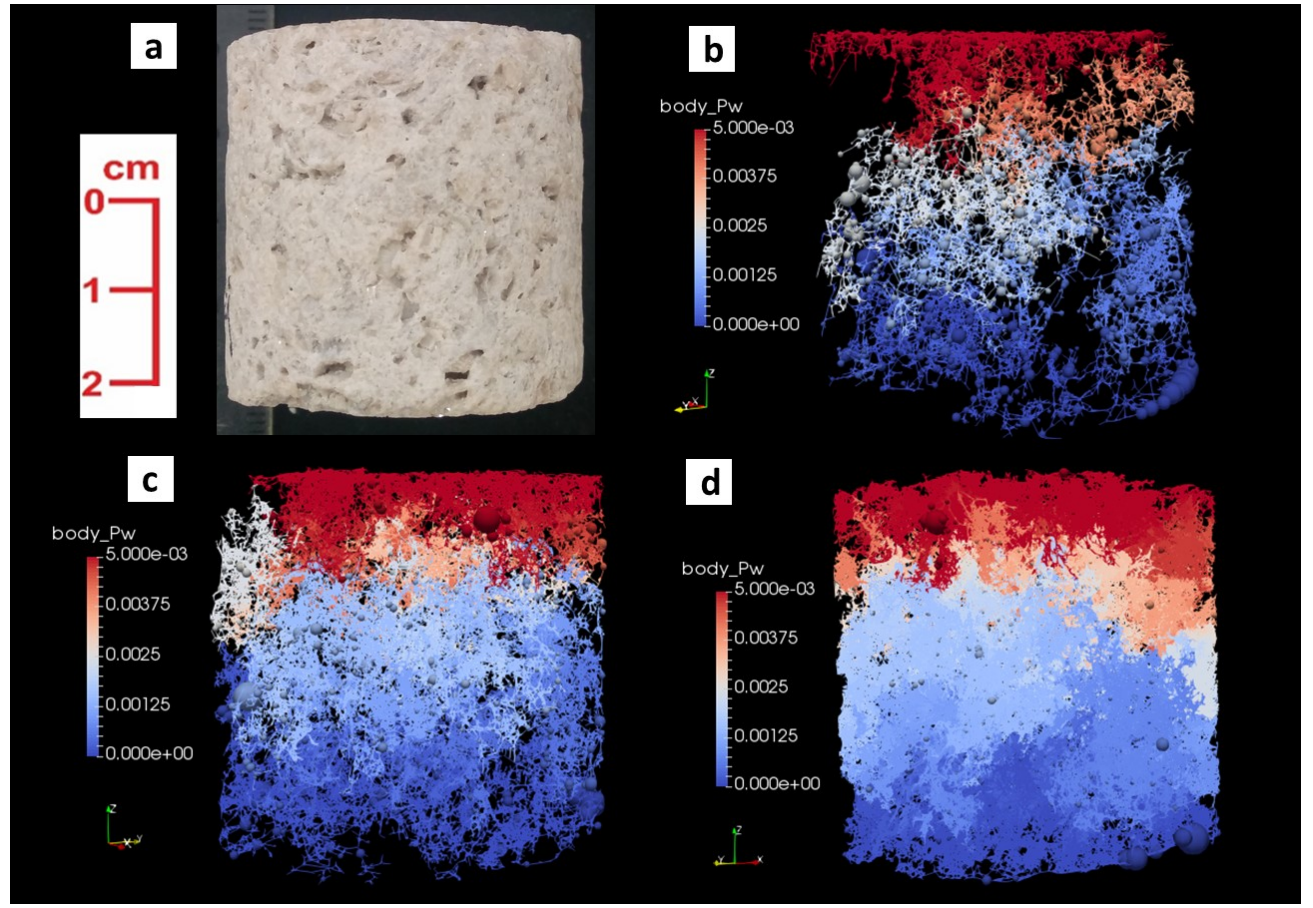

Fig. 12. (a) Image of plug 1-34A, and PNM results of the pressure field based on (b) $24.95 \mu \mathrm{m}$, (c) $18.17 \mu \mathrm{m}$, and (d) $9.97 \mu \mathrm{m}$ pixel size $\mu \mathrm{CT}$ images (pressure scales are in $\mathrm{Pa}$ ).

\section{CONCLUSIONS}

This study investigated experimentally and numerically several aspects of a coquina carbonate rock sample, a very close analogue to important pre-salt hydrocarbon reservoir rocks of Santos Basin (Brazil). A series of analyses were carried out on a thin section using optical microscopy, on a rock slab taken from a plug using SEM, EDS, XRD and $\mu \mathrm{CT}$, and on a larger plug using both $\mu \mathrm{CT}$ images and direct measurements. These analyses together with $3 \mathrm{D}$ imaging was used to examine the rock matrix composition and to verify and digitally reconstruct the pore systems, which provided much insight about the matrix and macropore fluid flow processes in the naturally very heterogeneous rock sample. Using PNM numerical simulations, we could estimate the absolute permeability of the rock slab and the entire plug, which presented a properly REV relative to the measured value. The experimental results were important to stablish significant correlations for the entire plug, mostly to obtain reliable information about the pore structure required in the modeling step. In our study we could detect bivalve and ostracode shells within the coquina sample and identify mesopores and macropores providing the main pathways for fluid flow inside the almost pure calcite rock sample. Digital reconstruction of the pore system, along with detailed experimental analyses, allowed us to construct and use the PNM models with confidence. The models were also used to verify the main aspects related to fluid flow modeling: $(i)$ rock slab models provided less accurate permeability values compared to the entire plug due to their volumes below the REV; (ii) pore throat radii calculated with harmonic averages gave the best results for the absolute permeability; and (iii) higher $\mu \mathrm{CT}$ resolution images provided the best result for the permeability according to the experimental data for the entire plug. In order to generate more realistic pore systems for the coquinas, we intend to use additional experimental techniques like nuclear magnetic resonance to verify prevailing pore distributions, and to further improve the segmentation procedures for additional PNM studies, especially for multiphase flow conditions.
Acknowledgements. This research was carried out in association with ongoing R\&D projects registered as ANP 19027-2, "Desenvolvimento de infraestrutura para pesquisa e desenvolvimento em recuperação avançada de óleo - EOR no Brasil" (UFRJ/Shell Brasil/ANP) for setting-up an advanced EOR Lab facility for R\&D in Brazil, and ANP 20163-2, "Análise experimental da recuperação de petróleo para as rochas carbonáticas do pré-sal brasileiro através da injeção alternada de CO2 e água", both sponsored by Shell Brasil under the ANP R\&D levy as "Compromisso de Investimentos com Pesquisa e Desenvolvimento". This study was financed in part by the Coordenação de Aperfeiçoamento de Pessoal de Nível SuperiorBrasil (CAPES) - Finance Code 001. We acknowledge Professor Ricardo Tadeu, Olga Oliveira and Alessandra Machado from LIN/UFRJ for using their $\mu \mathrm{CT}$ equipment and their technical support with image acquisitions. We also acknowledge Professor Leonardo Borghi and the LAGESED/UFRJ team for geological discussions, Adão Gonçalves from LIAP/UFRJ for the SEM-EDS analysis, Petrobras Research Center (CENPES) for the XRD analyses, and the LRAP/UFRJ team for sample preparation and petrophysical measurements.

\section{REFERENCES}

Al-Raoush, R.I., Willson, C.S., 2005. A pore-scale investigation of a multiphase porous media system. Journal of Contaminant Hydrology, 77, 67-89.

Andrä, H., Combaret, N., Dvorkin, J., Glatt, E., Han, J., Kabel, M., Zhan, X., 2013. Digital rock physics benchmarks - part I: Imaging and segmentation. Comput. Geosci., 50, 25-32.

ANP - Agência Nacional do Petróleo, Gás Natural e Biocombustíveis. 2018. Anuário estatístico brasileiro do petróleo, gás natural e biocombustíveis: 2018. Available at www.anp.gov.br/publicacoes/anuarioestatistico/anuario-estatistico-2018.

Ayachit, U., 2015. The ParaView Guide: A Parallel Visualization Application, Kitware. ISBN 978-1930934306

Azambuja Filho, N.C., Arienti, L.M., Cruz, F.E.G., 1998. Guidebook to the rift-drift Sergipe-Alagoas passive margin basin, Brazil. In: AAPG International Conference \& Exhibition, 1998, Rio de Janeiro, Brazil, AAPG/PETROBRAS 
Blunt, M.J. 2001. Flow in porous media - pore-network models and multiphase flow. Current Opinion in Colloid \& Interface Science, 6, 3, 197-207.

Blunt, M.J., Bijeljic, B., Dong, H., Gharbi, O., Iglauer, S., Mostaghimi, P., Paluszny, A., Pentland, C., 2013. Pore-scale imaging and modelling. Adv. Water Resour., 51, 197-216.

Buades, A., Coll, B., Morel, J.L., 2005. A non local algorithm for image denoising. IEEE Int. Conf. Computer Vision and Pattern Recognition, CVPR 2005, 2, 60-65.

Bultreys, T., Van Hoorebeke, L., Cnudde, V., 2015. Multi-scale, micro-computed tomography-based pore network models to simulate drainage in heterogeneous rocks. Adv. Water Resour., 78, 36-49.

Bultreys, T., De Boever, W., Cnudde, V., 2016. Imaging and imagebased fluid transport modeling at the pore scale in geological materials: A practical introduction to the current state-of-the-art. EarthSci. Rev., 155, 93-128.

Cnudde, V., Boone, M.N., 2013. High-resolution X-ray computed tomography in geosciences: A review of the current technology and applications. Earth-Sci. Rev., 123, 1-17.

Campos Neto, O.D.A., Lima, W.S, Cruz, F.G., 2007. Bacia de SergipeAlagoas. Boletim de Geociencias da Petrobras, 15, 2, 405-415.

Corbett, P.W., Estrella, R., Rodriguez, A.M., Shoeir, A., Borghi, L., Tavares, A.C., 2016. Integration of cretaceous Morro do Chaves rock properties (NE Brazil) with the Holocene Hamelin Coquina architecture (Shark Bay, Western Australia) to model effective permeability. Petrol. Geosci., 22, 2, 105-122.

Corbett, P.W.M., Wang, H., Câmara, R.N., Tavares, A.C., Borghi de Almeida, L.F., Perosi, F., Bagueira, R., 2017. Using the porosity exponent $(\mathrm{m})$ and pore-scale resistivity modelling to understand pore fabric types in Coquinas (Barremian-Aptian) of the Morro do Chaves Formation, NE Brazil. Marine and Petroleum Geology, 88, 628-647.

Dal Ferro, N., Charrier, P., Morari, F., 2013. Dual-scale $\mu$ CT assessment of soil structure in a long-term fertilization experiment. Geoderma, 204, 84-93.

De Boever, W., Derluyn, H., Van Loo, D., Van Hoorebeke, L., Cnudde, V., 2015. Data-fusion of high resolution X-ray CT, SEM and EDS for 3D and pseudo-3D chemical and structural characterization of sandstone. Micron, 74, 15-21.

de Vries, E.T., Raoof, A., van Genuchten, M.T., 2017. Multiscale modelling of dual-porosity media: a computational pore-scale study flow and solute transport. Adv. Water Resour., 105, 82-95.

Doyen, P.M., 1988. Permeability, conductivity, and pore geometry of sandstone. J. Geophys. Res.: Solid Earth, 93, B7, 7729-7740.

Fäy-Gomord, O., Soete, J., Davy, C.A., Janssens, N., Troadec, D., Cazaux, F., Caline, B., Swennen, R., 2017. Tight chalk: Characterization of the 3D pore network by FIB-SEM, towards the understanding of fluid transport. J. Petrol. Sci. Eng., 156, 67-74.

Fouard, C., Malandain, G., Prohaska, S., Westerhoff, M., 2006. Blockwise processing applied to brain micro-vascular network study. IEEE Trans. Medical Imaging, 25, 10, 1319.

Ghanbarian, B., Torres-Verdín, C., Skaggs, T.H., 2016. Quantifying tight-gas sandstone permeability via critical path analysis. Adv. Water Res., 92, 316-322.

Ghanbarian, B., Torres-Verdín, C., Lake, L.W., Marder, M., 2018. Gas permeability in unconventional tight sandstones: Scaling up from pore to core. J. Petrol. Sci. Eng., 173, 1163-1172.

Goldstein, J.I., Newbury, D.E., Joy, D.C, Lyman, C.E., Echlin, P., Lifshin, E., Sawyer, L., Michael, J., 2003. Scanning Electron Microscopy and X-Ray Microanalysis. 3rd ed. Springer, New York. ISBN 978-1-4615-0215-9

Hemes, S., Desbois, G., Urai, J.L., Schröppel, B., Schwarz, J.O., 2015. Multi-scale characterization of porosity in Boom Clay (HADES-level, Mol, Belgium) using a combination of X-ray $\mu$-CT, 2D BIB-SEM and FIB-SEM tomography. Micropor. Mesopor. Mat., 208, 1-20.

Hillier, S., 1994. Pore-lining chlorites in siliciclastic reservoir sandstones: electron microprobe, SEM and XRD data, and implications for their origin. Clay Miner., 29, 665-679.

Iassonov, P., Gebrenegus, T., Tuller, M., 2009. Segmentation of X-ray computed tomography images of porous materials: A crucial step for characterization and quantitative analysis of pore structures. Water Resour. Res., 45, 9-20.

Jafari, S., Yamamoto, R., Rahnama, M., 2011. Lattice-Boltzmann method combined with smoothed-profile method for particulate sus- pensions. Phys. Rev. E., 83, 2, 026702.

Joekar-Niasar, V., Hassanizadeh, S.M., 2012. Analysis of fundamentals of two-phase flow in porous media using dynamic pore-network models: a review. Crit. Rev. Environ. Sci. Technol., 42, 1895-1976.

Katz, A.J., Thompson, A.H., 1986. Quantitative prediction of permeability in porous rock. Physical Rev. B, 34, 11, 8179.

Kaczmarczyk, J., Dohnalik M., Zalewska, J., 2011. Evaluation of Carbonate Rock Permeability, with the Use of X-ray Computed Microtomography. Nafta-Gaz Rok, 67, 4, 233-239.

Kittler, J., Illingworth, J., 1986. Minimum error thresholding: Pattern recognition, 19, 1, 41-47. https://doi.org/10.1016/0031-3203(86)90030-0

Luna, J, Perosi, F.A., Dos Santos Ribeiro, M.G., Souza, A., Boyd, A., De Almeida, L.F.B, Corbett, P.W.M., 2016. Petrophysical rock typing of Coquinas from the Morro do Chaves Formation, Sergipe-Alagoas Basin (Northeast Brazil). Braz. J. Geophys., 34, 4, 509-521.

Machado, A.C., Teles, A.P., Pepin, A., Bize-Forest, N., Lima, I., Lopes, R.T., 2016. Porous media investigation before and after hydrochloric acid injection on a pre-salt carbonate coquinas sample. Applied Radiation and Isotopes, 110,160-163.

Newbury, E.D., Ritchie, N.W.M., 2013. Is scanning electron microscopy/energy dispersive X-ray spectrometry (SEM/EDS) quantitative? Scanning, 35, 141-168.

Rabbani, A., Assadi, A., Kharrat, R., Dashti, N., Ayatollahi, S., 2017. Estimation of carbonates permeability using pore network parameters extracted from thin section images and comparison with experimental data. J. Nat. Gas Sci. Eng., 42, 85-98.

Ramstad, T., Øren, P.E., Bakke, S., 2010. Simulation of two-phase flow in reservoir rocks using a lattice Boltzmann method. Soc. Pet. Eng. J., 15, 917-927.

Raoof, A., Hassanizadeh, S.M., 2010. A new method for generating pore-network models of porous media. Transp. Porous Media, 81, 3, 391-407.

Raoof, A., Hassanizadeh, S.M., Leijnse, A., 2010. Upscaling transport of adsorbing solutes in porous media: pore-network modeling. Vadose Zone J., 9, 3, 624-636.

Raoof, A., Hassanizadeh, S.M., 2012. A new formulation for porenetwork modeling of two-phase flow. Water Resour. Res., 48, 1.

Raoof, A., Nick, H.M., Hassanizadeh, S.M., Spiers, C.J., 2013. PoreFlow: A complex pore-network model for simulation of reactive transport in variably saturated porous media. Comp. Geosci., 61,160-174.

Sezgin, M., Sankur, B., 2004. Survey over image thresholding techniques and quantitative performance evaluation. J. Electron. Imaging, 13, 1, 146-165.

Shah, S.M., Gray, F., Crawshaw, J.P., Boek, E.S., 2015. Microcomputed tomography porescale study of flow in porous media: effect of voxel resolution. Adv. Water Resour., 95, 276-287.

Tavares, A.C., Borghi, L., Corbett, P., Nobre-Lopes, J., Câmara, R., 2015. Facies and depositional environments for the coquinas of the Morro do Chaves Formation, Sergipe-Alagoas Basin, defined by taphonomic and compositional criteria. Braz. J. Geol., 45, 3, 415-429.

Thijssen, J., 2007. Computational Physics. Cambridge University Press, Cambridge. ISBN 9781139171397. https://doi.org/10.1017/CBO9781139171397

Thompson, D.L., Stilwell, J.D., Hall, M., 2015. Lacustrine carbonate reservoirs from Early Cretaceous rift lakes of Western Gondwana: PreSalt coquinas of Brazil and West Africa. Gondwana Res., 28, 26-51.

Vik, B., Bastesen, E., Skauge, A., 2013. Evaluation of representative elementary volume for a vuggy carbonate rock - Part I: Porosity, permeability, and dispersivity. J. Petrol. Sci. Eng., 112, 36-47.

Wildenschild, D., Vaz, C.M.P, Rivers, M.L., Rikard, D., Christensen, B.S.B., 2002. Using X-ray Computed Tomography in Hydrology: Systems, Resolutions, and Limitations. J. Hydrol., 267, 3, 285-297.

Wildenschild, D., Sheppard, A.P., 2013. X-ray imaging and analysis techniques for quantifying pore-scale structure and processes in subsurface porous medium systems. Adv. Water Resour., 50, 217-246.

Wojdyr, M., 2010. Fityk: a general-purpose peak fitting program. J. Appl. Crystall., 43, 5, 1126-1128.

Zhang, D., Zhang, R., Chen, S., Soll, W.E., 2010. Pore scale study of flow in porous media: Scale dependency, REV, and statistical REV. Geophys. Res. Lett., 27, 8, 1195-1198.

Received 13 March 2019 Accepted 16 April 2019 